\title{
CARMEN MIRANDA, O ESTADO NOVO E O DISCURSO VERDADEIRO
}

\author{
Gabriel Veppo de Lima (UFSC) ${ }^{1}$
}

\begin{abstract}
Resumo: O presente texto busca armar, sob a perspectiva da parrésia tal como investigada por Michel Foucault uma leitura sobre o episódio em que a artista Carmen Miranda foi recebida friamente por uma plateia composta de representantes do Estado Novo no Cassino da Urca em 1940 . Partindo deste acontecimento, entendido como um choque entre visões diferentes sobre a questão do nacional, e da letra da canção Disseram que eu voltei americanizada, este estudo levanta uma discussão sobre quais as aproximações e distâncias entre Carmen Miranda, o Estado Novo e o discurso verdadeiro da parrésia.
\end{abstract}

Palavras-chave: Carmen Miranda; parrésia; discurso verdadeira; identidade nacional; música popular.

No ano de 1983, Michel Foucault ministrou um curso no Collège de France sobre a noção de parrésia. Em seu desenvolvimento, o autor se vale, entre outros, de trechos de textos da Grécia Antiga, a saber, Édipo Rei de Sófocles, Íon de Eurípedes e Laques, dos diálogos de Platão, para definir um tipo de discurso da verdade e a coragem implicada em sua performance. Tal discurso está diretamente ligado à relação de governabilidade entre a esfera pública e a privada, como já anuncia o título do livro, Governo de si e do outro, que reúne os textos das conferências proferidas por Foucault ao longo do curso, e é sob a perspectiva da parrésia foucaultiana que este trabalho pretende projetar uma leitura sobre a viagem retorno/passagem de Carmen Miranda pelo Brasil em meados do ano de 1940, quando a artista se viu diante de acusações públicas de que havia se americanizado e já não tinha mais o jeito típico brasileiro. Toda a discussão em torno da questão da brasilidade/americanização de Carmen Miranda é, em última instância, a discussão do problema da legitimidade discursiva de Carmen Miranda enquanto artista e símbolo nacional. Este problema está inserido na tensão entre identidade e pertencimento e, assim como nos trechos escolhidos por Michel Foucault para tratar da parrésia, a estória ${ }^{2}$ da passagem de Carmen Miranda pelo país naquele momento é uma estória sobre um tipo de discurso e o direito de fazê-lo. Quando tratamos do caso de Carmen Miranda e as acusações de sua americanização, ou seja, sua perda de autenticidade brasileira,

\footnotetext{
${ }^{1}$ Pesquisador do Núcleo de Estudos Literários \& Culturais Nelic-Ufsc; Doutorando do Programa de Pós Graduação em Literatura da UFSC; Bolsista Capes. E-mail: gabrielveppo@gmail.com

2 O termo foi adotado com o intuito de assumir a carga de ficção implicada na leitura. Pretendese, antes de qualquer coisa, contar uma estória possível e abdicar de qualquer compromisso científico historicista.
} 
estamos pisando no campo das identidades culturais circunscritas pela ideia de nação ${ }^{3}$, a comunidade imaginada de que trata Benedict Anderson. Este campo é palco de uma multiplicidade de discursos que, de um modo bastante simplista, podemos dividir em três grupos, três forças discursivas, três vozes. Em primeiro lugar, existe a voz do discurso estatal, oficial, comprometido com o projeto da nação na posição de instituição. Em segundo lugar, há os meios de comunicação e os produtores de conteúdos artísticos, sob a tutela e subsídio do Estado; desse modo, têm-se o rádio, o cinema e o teatro de revista como meios privilegiados de massificação da identidade, via entretenimento, diversão, e que são comprometidos com o projeto de nação, na medida em que seus interesses políticos e econômicos dependem de uma unidade cultural, um mercado consumidor. E, por último, há também a comunidade civil, vozes da sociedade civil, as pessoas que não pertencem, ou não estão imediatamente ligadas aos interesses do Estado ou do capital privado. São esses os cidadãos/consumidores, aqueles que serão consumidores e atores de uma identidade que é dirigida para eles, com eles e a partir deles ${ }^{4}$.

Sobre Carmen Miranda, o questionamento de sua brasilidade em si é um evento sintomático de sua posição, seu status quo enquanto representante de uma identidade brasileira, ou melhor, de sua legitimidade de se apropriar de forma verdadeira de cada uma das vozes dentro desse jogo de representações. Esta posição de Carmen é um lugar discursivo, o ponto onde o artista popular se vale da voz, da representação da voz, de um povo ideal para falar a partir desta posição discursiva, sobre e para este povo ou, se preferirmos, esta comunidade. Este lugar, como o próprio acontecimento do questionamento desnuda, é regido por uma lógica que transpassa as noções de legitimidade, autenticidade e originalidade. $\mathrm{Na}$ condição de ídolo nacional, o artista popular pode assumir um papel de porta-voz, um estatuto de portador da cultura, disseminador de um denominador comum, alguém a quem é confiada a tarefa de cultivar o que é "da terra", para se valer de uma expressão tradicionalista, e essa tarefa passa pelo crivo da crítica dos diversos agentes sociais. A legitimidade do artista enquanto portador de um objeto comum está sempre sob o jugo da opinião pública, de sua adequação àquilo que deve ser representado enquanto nacional e adequado segundo o discurso de cada uma daquelas três vozes referidas anteriormente. Sobre a representação da identidade nacional, a idealização de uma brasilidade, tão exacerbada em alguns momentos históricos, é interessante notar que ela assume papel de crise,

\footnotetext{
3 Nação como uma comunidade imaginada, compartida entre pessoas que jamais se encontrarão, mas que têm em comum essa comunidade subjetiva.

4 No interior da polissemia da ideia de nação, o projeto nacionalista se apropria de alguns discursos e práticas culturais para elevar ao estatuto de símbolo de unidade aquilo que é próprio da fragmentação, da heterogeneidade. Daí o samba carioca ser o ritmo nacional e não o frevo pernambucano e sua embaixatriz ser uma baiana alegórica, que remonta às suas raízes históricas.
} 
aporia, em outros momentos. Um exemplo que pode ser muito elucidativo sobre o dinamismo que rege este jogo de representações é a figura do mestiço e a ideia da mestiçagem que sofreu uma inversão no inicio do século XX, de problema a ser evitado via europeização da população, a mestiçagem passou a ser um valor positivo dentro da ideia de nação brasileira ${ }^{5}$.

A própria Carmen Miranda é um exemplo das antinomias do processo identitário nacional. Nascida em Portugal, branca de olhos verdes, vestida com o abada das baianas quituteiras e tida como a imperatriz do samba, ritmo brasileiro oriundo das batucadas da antiga escravatura, Carmen Miranda era a sambista que o Brasil aceitava, que podia circular na mídia. Vários outros aspectos podem ser levantados sobre a questão da identidade nacional, sua representação e a arte popular como um todo, mas este trabalho pretende deter-se em alguns pontos específicos do caso de Carmen Miranda. Para tanto, é importante começar com a estória de um show que a artista fez em 15 de julho de 1940 no Cassino da Urca a pedido da então primeira dama, Darcy Vargas.

[...] Marchamos para um futuro diverso de quanto conhecíamos, em matéria de organização econômica, social ou política, e sentimos que os velhos sistemas e formas antiquadas entram em declínio. Não é, porém, o fim da civilização, mas o início tumultuoso e fecundo de uma nova era. Os povos vigorosos, aptos à vida, necessitam seguir o rumo de suas aspirações, em vez de se deterem na contemplação do que se desmorona e tomba em ruína. É preciso, portanto, compreender nossa época e remover o entulho das ideias mortas e dos ideais estéreis (VARGAS apud CASTRO, 2005, p. 242).

O trecho acima reproduz parte do discurso de Getúlio Vargas no dia 11 de junho de 1940. No contexto de seu pronunciamento, suas referências são claramente a "novidade" política do eixo nazifascista da Alemanha e Itália e o velho liberalismo dos Estados Unidos da América. No mesmo discurso, Vargas vai declarar que passou a era dos liberalismos imprevidentes, em uma clara alusão aos países que formaram o eixo dos aliados na Segunda Grande Guerra. É neste contexto político que Carmen Miranda volta ao Brasil, depois de um ano de sucesso nos E. U. A. Em dez de julho do mesmo ano, Carmen desembarcou no Rio de Janeiro. Recebida por uma multidão, e pelo próprio Estado Novo, ou seja, pelo DIP 6 , a cantora, logo no cais, deparou-se com questionamentos sobre sua brasilidade por parte da imprensa. Ao insistir para os jornalistas estadunidenses de que cantava em português, não em espanhol, a

5 É evidente que se trata de uma mudança paradigmática no âmbito das discussões intelectuais da época.

${ }_{6}$ Departamento de Imprensa e Propaganda 
artista alimentou rumores de que não se sentia brasileira, mas sim portuguesa, que era de fato sua naturalidade 7 .

Carmen Miranda aceitou um convite da primeira dama, Darcy Vargas, para cantar no Cassino da Urca em uma noite beneficente. Esta apresentação foi a primeira no país depois de sua temporada pelos Estados Unidos, mas se mostrou um suplício. Com uma plateia compostas por uma fileira de mesas em que constavam nomes importantes do governo Vargas, seus números adaptados para o gosto do público estadunidense causaram constrangimentos na plateia, que respondia friamente a cada performance. Aqui vale a pena, ou é justificável, uma citação para se ter uma ideia da plateia do Cassino naquela noite:

[...] Presentes, além da primeira dama, dona Darcy Vargas, estavam sua filha
Alzirinha e o marido desta, Ernani do Amaral Peixoto, interventor do estado do
Rio; general Eurico Gaspar Dutra, ministro da Guerra; general Góes Monteiro,
chefe do Estado-Maior do Exército; Francisco Campos, ministro da Justiça;
Waldemar Cromwell Falcão, ministro do Trabalho; Gustavo Capanema,
ministro da Educação; vice-almirante Aristides Guilhem, ministro da Marinha;
coronel Cordeiro de Faria, interventor do Rio Grande do Sul; capitão Filinto
Müller, chefe de polícia do Distrito Federal; capitão Batista Teixeira, do
Departamento de Segurança Política e Social; "coronel" Bejo Vargas, bon-
vivant, lobista e primeiro-irmão; Lourival Fontes, chefe do DIP; Júlio Barata,
diretor da Divisão de Rádio do DIP; Assis Figueiredo, diretor da Divisão de
Turismo do DIP; e o radialista Felicio Mastrangelo, italiano nato e mais tarde
acusado de quinta-coluna no Brasil por vários jornalistas (CASTRO, 2005, p.
250).

Foi diante desta plateia ufanista que Carmen Miranda entrou no palco dizendo "Good night, people" e a cada número constatou que não estava agradando até que deixou o palco chorando após quatro canções (CASTRO, 2005, p. 250).

Hoje é possível pensar no acontecimento considerando a conjectura da época, seu contexto histórico e o público, que era a alta patente do Estado ditatorial de Getúlio Vargas, portanto com inclinações nacionalistas mais claras, o que torna as implicações da apresentação de Carmen mais táteis. Diante dos textos disponíveis atualmente, o show do Cassino da Urca nos parece uma gafe, uma falta de sensibilidade da artista e do seu pessoal. Mas é preciso pôr em conta que uma artista do calibre de Carmen tinha uma estrutura por trás de si e que esta, por sua vez, tenha certo jogo de cintura, certa perspicácia, ou ainda, mesmo que a artista tenha tomado sozinha a decisão de participar do show, uma ingenuidade pura me parece uma resposta simplista. O papel, o estatuto de Carmen, permitia, e de fato permitiu, que ela se chocasse com os interesses do Estado Novo. Não de modo proposital, mas

7 Cf. CASTRO, 2005, p. 248.

fragmentum, N. 36. Laboratório Corpus: UFSM, Jan./ Mar. 2013 
de algum modo, para ela, seu sucesso nos Estados Unidos era o sucesso do Brasil lá fora; já para os governantes e suas aspirações políticas diante do contexto político internacional, a artista, que havia ido aos Estados Unidos representar a cultura nacional, havia se tornado um constrangimento. É preciso notar o caráter festivo e glamoroso de um show, o primeiro desde seu retorno, para uma plateia como esta. Ao chegar ao Brasil, a artista gozava de aprovação deste mesmo Estado que não gostou do que viu no Cassino da Urca e, justamente por não gostar do que viu, é sintomático de um choque, de uma colisão de visões, de ideais de uma representação da identidade nacional. A questão mais interessante deste acontecimento é justamente: o que em Carmen Miranda desagradou à plateia da alta patente oficial? $\mathrm{O}$ evento em si era uma prova da boa relação entre o Estado e a artista, diga-se de passagem, a maior artista brasileira na época, o convite da primeira dama, a recepção dias antes no cais, com direito a passeio em carro aberto pela cidade, tudo isso era prova de que Carmen Miranda era a menina dos olhos de todos.

Quando deixou o país, um ano antes do show no Cassino da Urca, Carmen Miranda foi visitar Getúlio Vargas em Caxambu para uma pequena apresentação particular. Junto com o Bando da Lua, seguiria para Nova Iorque para se apresentar na Feira Mundial, era ela a representante do país numa feira onde as nações exibiam suas culturas e seus negócios. O próprio Bando da Lua, por interferência da filha do presidente, Alzirinha Vargas, só pôde embarcar para os Estados Unidos com subsídio do Estado, pois o empresário Lee Shubert não tinha interesse no grupo musical. Essa interferência se deu por interesse de Getúlio em divulgar a cultura nacional no exterior, o próprio argumento para a insistência do acompanhamento do Bando da Lua passava por uma alegada incapacidade dos músicos estadunidenses de tocar adequadamente o ritmo brasileiro. Assim, era imperativo que o samba fosse tocado por gente da terra, que conhecesse no sangue o ritmo sincopado, quase como uma questão de direito e competência determinada pelo nascimento, pelo pertencimento a uma cultura.

A cena do Cassino da Urca é importantíssima para entender a polifonia do discurso identitário. Um ano antes da apresentação, Carmen havia deixado o Brasil com a incumbência de levar o samba para o exterior, traduzir para as outras culturas o que havia de mais brasileiro, mais nacional, pois, naquele momento, como ainda é hoje, este símbolo é o samba. Se projetarmos o que viria a ser a carreira da artista nos Estados Unidos, o próprio processo identitário estadunidense por meio do cinema caricaturou o Brasil e toda a América Latina, forçando sotaques e tipos nas representações dessas culturas. Carmen Miranda se beneficiou e foi vítima desse processo, mas estava antes de tudo ligada ao processo identitário brasileiro, e, nele, sua participação se deu como uma artista do caricato, do exagero, do carnavalesco. Antes de retornar ao Brasil em 1940, o colunista Lucius Beebe perguntou a Carmen se as 
brasileiras se vestiam como ela, ao que Carmen respondeu que "não, que aquela era uma roupa quase de Carnaval"; e, ao ser questionada por Beebe se seus gestos eram parte do samba "autêntico", ela respondeu: "Não. Eles fazem parte da minha interpretação e só servem para dar uma ideia do que é o samba, que é a dança nacional do Brasil" (CASTRO, 2005, p. 224). O desfile das escolas de samba só foi oficializado pelo poder público em 1937 e seu passado é repleto de histórias de perseguição e preconceito, mas, em 1939, Carmen Miranda já afirmava categoricamente a um jornalista americano que o samba era a dança nacional. Em sua história, o ritmo nacional por excelência já contou com o mesmo crédito que o funk carioca conta hoje, considerado de baixo calão e pobre em termos técnicos musicais e, mais significativamente, em um período da história da música popular brasileira, "samba" foi considerado um sinônimo para o termo tango.

Se Carmen saiu do Brasil com a incumbência de representar a cultura do país, a descrição, nas diversas biografias e jornais, de sua recepção na chegada ao cais, nos diz pelo menos duas coisas importantes para este estudo. Em primeiro lugar, todos ${ }^{8}$ ainda viam Carmen Miranda, incluindo a própria artista, como portadora do estatuto de representante, intérprete da cultura brasileira. Em segundo lugar, é importante perceber que este ponto de colisão entre a plateia do Cassino da Urca e Carmen Miranda, a colisão das representações, obviamente era a aproximação de Carmen com a cultura estadunidense, sobre a qual a cultura brasileira deveria prevalecer e jamais se submeter. A performance no Cassino foi constrangedora para o Estado pelo seu tom internacional; para Carmen, era prova de seu sucesso, do sucesso do Brasil que ela representava como cidadã e artista e que, de fato, lutava com todas as suas forças para obter um lugar entre as nações ditas de primeiro mundo. Dois eventos significativos ocorreram em um pequeno espaço de tempo: em menos de uma semana, a artista viveu um episódio de ídolo ovacionado publicamente para, logo em seguida, ver-se como a vergonha nacional para uma plateia ligada ao Estado. O mal-estar causado pela fria recepção no Cassino da Urca fez com que a cantora procurasse seus compositores e pedisse novas canções para eles. A canção mais expressiva entre as que foram compostas a pedido da artista é sem dúvida Disseram que eu voltei americaniz̧ada. Uma espécie de resposta às acusações que recaíram sobre ela. Essa resposta é um tipo de discurso verdadeiro, cantado por Carmen Miranda, falando de si e de seu pertencimento à cultura brasileira.

8 Sem dúvidas, antes mesmo de Carmen embarcar para os Estados Unidos, já a acusavam de americanizada, pouco autêntica, mas os rumores de que ela estava se americanizando foram pouco importantes até o momento do show do Cassino da Urca. 
Disseram que eu voltei americanizada

\author{
Me disseram que eu voltei americanizada \\ Com o burro do dinheiro \\ Que estou muito rica \\ Que não suporto mais o breque do pandeiro \\ E fico arrepiada ouvindo uma cuíca \\ Disseram que com as mãos \\ Estou preocupada \\ E corre por aí \\ Que eu sei certo zum zum \\ Que já não tenho molho, ritmo, nem nada \\ E dos balangandãs já nem existe mais nenhum \\ Mas pra cima de mim, pra que tanto veneno \\ Eu posso lá ficar americanizada \\ Eu que nasci com o samba e vivo no sereno \\ Topando a noite inteira a velha batucada \\ Nas rodas de malandro minhas preferidas \\ Eu digo mesmo eu te amo, e nunca "I love you" \\ Enquanto houver Brasil \\ $\mathrm{Na}$ hora da comidas \\ Eu sou do camarão ensopadinho com chuchu
}

Essa primeira parte da música lista uma série de características negativas do eu lírico, coisas que dizem sobre ele e dizem na forma de boatos. É interessante notar que a questão da americanização é o tema central da canção, isso se reforça pelo título. Mas, se os versos onde aparece o termo americanizada fossem suprimidos, todas as características negativas que são enumeradas são facilmente encontradas na elite brasileira da época: aqueles mesmos que aplaudiram a cantora friamente no Cassino da Urca não compartilham desse gosto pela batucada, não ficariam no sereno nas rodas de samba. Logo, mesmo que não sejam americanizados, jamais poderiam ser $\mathrm{o}$ brasileiro do qual nos fala a letra. Esta canção, composta por Vicente Paiva e Luiz Peixoto, é uma resposta à alegada americanização de Carmen e, ao mesmo tempo, uma reafirmação dos valores populares da artista. Se, por um lado, foi o pedido de Carmen por novo repertório depois do desastroso show do Cassino da Urca que precipitou essa canção resposta, por outro, ela parece não ignorar as diferenças entre o estilo de vida do brasileiro típico das letras de samba e a forma como vivem aqueles que compuseram a plateia que recebeu friamente a artista. $\mathrm{O}$ discurso da canção se direciona à opinião pública, para uma plateia de ouvintes populares; mas, por via deste desvio, acerta em cheio na diferença de perspectivas. Ao reafirmar seu gosto pela batucada, a canção desqualifica qualquer crítica oriunda da elite. Um aspecto interessante da canção composta por Paixa e Peixoto é justamente o modo como o eu lírico afirma sua brasilidade. Sua estratégia é devolver ao Estado sua própria crítica. 
A recepção fria da Urca era um aviso, como quem diz: "Essa voz que você está usando, isto que você está representando não é o Brasil que nós queremos, não é o Brasil de verdade para nós". A canção parece se voltar ao povo, mas de um modo disfarçado, pois parece estar muito preocupada em separar a artista da imagem da elite, da aristocracia e também é um aviso, uma mensagem que diz: "Olha, você que me acusa de não ser brasileira, que diz que eu sou uma falsa baiana e me critica por perder o ritmo, por balançar as mãos de um modo exagerado, você não tem sequer o direito de me questionar, pois a brasilidade que você diz estar perdida em mim não condiz com você, não é verdadeira para você". O Estado manifestou-se no Cassino da Urca, mas suas críticas pararam por aí, pois entre a política estatal, a opinião pública e a economia de mercado existe uma relação que talvez tenha sido importante para que o desagrado da elite política não tivesse maiores consequências além do mal-estar da apresentação no Cassino. Adorada pelo povo e muito rentável ao mercado audiovisual, Carmen foi blindada pelo seu estatuto público e pôde retornar aos Estados Unidos onde, lá sim, era inquestionavelmente o símbolo da identidade nacional brasileira. Mas é sintomático que todo o resto de sua carreira se dê nos Estados Unidos, afinal, a cantora saíra ressentida de sua breve passagem pelo país em 1940.

Podemos dizer que existe um conflito entre duas forças discursivas, uma é a ideia de uma identidade que tinha o discurso representado pelo Estado, pelo governo Vargas, ou seja, uma ideia de um Brasil que, antes de tudo, deveria ser trabalhador, sempre feliz, educado e civilizado; a outra é o discurso popular sobre uma brasilidade carioca, que preferia o samba e a vida na boemia ao trabalho fabril. O lugar ocupado por Carmen Miranda apropriase tanto do discurso oficial ${ }^{9}$, em letras como Recenseamento:

\footnotetext{
Obediente eu sou a tudo que é da lei,

Fiquei logo sossegada e falei então,

- O meu moreno é brasileiro, é fuzileiro,

E é quem sai com a bandeira do seu batalhão!

A nossa casa não tem nada de grandeza

Nós vivemos na fartura, sem dever tostão

Tem um pandeiro, uma cuíca, um tamborim

Um reco-reco, um cavaquinho e um violão
}

quanto do discurso popular que prefere a batucada das rodas de malandros:

Eu posso lá ficar americanizada

Eu que nasci com o samba e vivo no sereno

\footnotetext{
${ }^{9}$ A canção não deixa de ser irônica quando o eu lírico fala das coisas que o Brasil lhe deu, "pão de açúcar sem farelo, pano verde amarelo...". Portanto, é um discurso aparentemente oficial, mas ilustra a maleabilidade da voz da artista na miríade de discursos possíveis.
} 
Topando a noite inteira a velha batucada

Nas rodas de malandro minhas preferidas

Eu digo mesmo eu te amo, e nunca "I love you"

Essa possibilidade de apropriação de qualquer discurso, de qualquer Phonê de forma legítima é a característica do estatuto de artista nacional, cantar as "coisas do Brasil", aquele que pode cantar as coisas brasileiras, pois reúne as precondições necessárias; portanto, quando canta, o faz com propriedade, de forma verdadeira ${ }^{10}$ e é uma verdade para o artista também, o intérprete. Para a maioria das pessoas que eram fãs de Carmen, havia, em suas canções e representações, uma brasilidade carioca, malemolente, que via a si mesma em interpretações das manifestações populares, na figura da baiana, do sambista malandro. O medo da americanização é um sintoma da importância da cultura estadunidense no cenário global, mas é também sintoma de um medo da alienação, o medo da perda da pureza, da autenticidade brasileira. Desse modo, a americanização tem influência negativa na legitimidade do artista perante o discurso do nacional.

Assim, a música popular fala verdades que são verdades em certos contextos discursivos, mas sempre fala do povo, de uma identidade, uma tonalidade típica da nação e está em constante articulação com estas forças discursivas, sempre ponderando para que nem uma ou outra se sobreponha. É bem verdade que a maioria do cancioneiro da música popular trata o malandro como o tipo nacional, e é a agenda do Estado que visava a colocar esse malandro para trabalhar, civilizar o tipo nacional. Mas todas as forças discursivas tinham uma relação de ponderação entre si. O governo possui o poder da censura, mas a massa é quem consome e, por isso, tem poder sobre aquilo que gosta. Essa verdade da qual se apropria o artista popular não é um tipo de parrésia, mas a noção deste tipo de discurso pode dar potência para a relação de forças discursivas do processo identitário na música popular. A condição formal para a verdadeira parrésia, segundo Foucault, é referente ao tipo de governo. Na democracia, quem faz uso da fala franca é um cidadão, cujo direito the permite o exercício político de dizer a verdade. No caso dos governos tiranos, é a figura de um conselheiro que faz uso da parrésia na forma de falas francas direcionadas ao príncipe. Pensando no contexto brasileiro de 1940, estamos diante de um Estado ditatorial, mas que é também um Estado absolutamente ligado à economia financeira, ao mercado. O poder é centralizado pelo regime de Getúlio, mas este precisa sempre pôr na balança os interesses do mercado, o capital financeiro que, em última instância, mede

\footnotetext{
10 Embora exista esse jogo, essa relação entre o artista e o discurso nacional, ou seja, sua legitimidade para fazê-lo, a priori não há uma relação entre esta legitimidade do artista e a parrésia foucaultiana que demanda uma implicação pessoal, um risco deliberadamente assumido por quem faz uso do discurso verdadeiro.
} 
forças com o governo. Não se trata de uma democracia, já que estamos falando de um regime ditatorial, nem de uma tirania propriamente dita, pois nem tudo é permitido ao governo diante da opinião pública e dos olhos do mercado. Assim, Getúlio Vargas não é um príncipe como Alexandre, nem o Brasil é uma democracia como foi Atenas antes da guerra do Peloponeso. De fato não existem as condições formais necessárias para uma parrésia foucaultiana, e a própria natureza do objeto do qual se fala uma verdade, a identidade nacional, já é em si uma impossibilidade. Exercer seu direito de parrésia para sua comunidade, como faz Péricles ao propor a continuidade da guerra com Esparta, é participar como cidadão da democracia ateniense; o caso de Carmen é um caso de simbolismo, pois ela ocupa um lugar representativo, e seu estatuto na sociedade não coincide com a cidadã Maria do Carmo Miranda da Cunha. Quanto a isso, ela mesmo ponderaria: "Coube-me a grande oportunidade e a grande honra de ser a intérprete das coisas brasileiras" e, logo adiante, já se adiantaria às críticas que posteriormente recairiam sob sua imagem, dizendo: "Eu quero que o americano conheça o samba, compreenda que o samba não é rumba. Não vou esquecer da minha terra. Nem me americanizar. Vou levar um pouco do Brasil" (MENDONÇA, 1999, p. 57). Carmen então entende seu estatuto de representante da cultura brasileira no exterior como uma oportunidade, não como um direito, embora já goze de reconhecimento popular suficiente para se sentir no direito de; além disso, a artista se vê como uma intérprete, e aqui é interessante frisar o caráter polissêmico do termo intérprete, podendo ser no sentido dramático que alude ao papel do artista, seja no teatro, no cinema, ou na música, e ainda mais sintomática é acepção do "tradutor", como o mediador de duas línguas diferentes, que no caso desnuda a visão de Carmen Miranda sobre seu papel de tradutora da cultura brasileira para o público estadunidense.

Impulsionada rapidamente ao sucesso após a gravação da marchinha de carnaval Pra você gostar de mim (Taí), a artista não foi a primeira, mas talvez tenha sido a maior vítima de um acontecimento que se repete na história da música popular brasileira. Pixinguinha foi acusado em 1928, por Cruz Cordeiro, de ser muito jazzístico ${ }^{11}$; na década de sessenta, a bossa nova vai sofrer as mesmas acusações, tendo como seu maior crítico o jornalista José Ramos Tinhorão, importante musicólogo brasileiro. Caetano Veloso e Gilberto Gil também vão sofrer duras críticas, vaias em festivais, por tocarem canções arranjadas com guitarras elétricas, na época símbolo nacional do imperialismo estadunidense na música. O problema da identidade nacional e suas representações através da música popular aproxima-se do problema descrito pelo discurso de Isócrates sobre a assembleia que estaria disposta a

11 Os choros Lamentos e Amigo do povo de autoria de Pixinguinha e Donga respectivamente. Ambos foram acusados, por Cruz Cordeiro, na revista Fonoarte, de utilizarem recursos jazzísticos em suas obras. Aqui se trata de uma crítica a duas obras e não aos artistas ou a todo o universo do choro. 
aceitar de bom tom críticas em formas teatrais, satíricas sobre suas falhas, mas não era capaz de aceitar essas mesmas críticas em uma assembleia de forma direta. A realidade identitária brasileira não corresponde ao mito da cultura nacional pura, autêntica, original, mas qualquer possibilidade de explicitação deste fato é rebatida como um atentado ao bem comum nacional. O Brasil em que Carmen vivia era americanizado e o mesmo pode ser dito para todas as épocas quando o discurso nacionalista acusou algum artista de americanizado. A representação da identidade nacional é a projeção de um ideal sobre a realidade, sobre a realidade de uma ex-colônia portuguesa cheia de aspirações patrióticas. O mito da pureza da raça ariana trazido pelos europeus, pela impossibilidade lógica de seu funcionamento para a sociedade brasileira, tomou a forma de mito da pureza da cultura, do samba de "raiz", da "verdadeira baiana". Duas outras canções são significativas sobre a americanização da cultura brasileira, da música, em especial do samba enquanto símbolo do nacional. A primeira é a canção Chiclete com Banana de autoria de Jackson do Pandeiro e Gordurinha:

\author{
Chiclete com Banana \\ Só ponho bebop no meu samba \\ Quando o Tio Sam pegar no tamborim \\ Quando ele pegar no pandeiro e no zabumba \\ Quando ele entender que o samba não é rumba \\ Aí eu vou misturar Miami com Copacabana \\ Chicletes eu misturo com banana \\ E o meu samba vai ficar assim \\ Bebop, Bebop, Bebop \\ Quero ver a grande confusão \\ Bebop, Bebop, Bebop, \\ É o samba-rock, meu irmão \\ Mas em compensação \\ Quero ver o boogie-woogie de pandeiro e violão \\ Quero ver o tio Sam de frigideira \\ Numa batucada brasileira
}

No discurso da letra, a questão da cultura estadunidense está presente, mas existe uma proposta de convivência, um meio termo entre uma possível americanização e a preservação de uma brasilidade. Esse olhar de quem propõe um intercâmbio entre Brasil e os Estados Unidos se opõe, por exemplo, ao olhar do eu lírico da canção Influência do Jaž de Carlos Lyra: 
Influência do Jazz

Pobre samba meu

Foi se misturando se modernizando, e se perdeu

E o rebolado cadê?, não tem mais

Cadê o tal gingado que mexe com a gente

Coitado do meu samba mudou de repente

Influência do jazz

Quase que morreu

E acaba morrendo, está quase morrendo, não percebeu

Que o samba balança de um lado pro outro

O jazz é diferente, pra frente pra trás

E o samba meio morto ficou meio torto

Influência do jazz

No afro-cubano, vai complicando

Vai pelo cano, vai

Vai entortando, vai sem descanso

Vai, sai, cai... no balanço!

Pobre samba meu

Volta lá pro morro e pede socorro onde nasceu

Pra não ser um samba com notas demais

Não ser um samba torto pra frente pra trás

Vai ter que se virar pra poder se livrar

Da influência do jazz

Aqui o samba está morrendo, agonizando e deve voltar para o seu lugar de origem mitológica, o morro, lá onde surgiu o mais "puro" representante de uma brasilidade autêntica. O ponto de vista da canção compartilha dos ideais de pureza que vão circular pela história da música popular brasileira ao longo dos anos, mas é interessante notar que o autor, Carlos Lyra, é um dos expoentes da bossa nova, e a própria canção que ele compôs tem claras influências do jazz. Existe uma infinidade de canções falando sobre a questão da identidade nacional, de uma indesejada americanização. Disseram que en voltei americanizada é importante pela relação direta com o episódio do Cassino da Urca em 1940, e também pelo tipo de resposta que o texto representa. Buscando afastar do eu lírico, que representa Carmen e é representado por ela, as críticas e as acusações de americanização, o discurso da canção não é precisamente uma fala franca, uma parrésia; mas, de forma indireta, expõe a falta de autenticidade daqueles que criticam o eu lírico. O verso "e lá posso eu ficar americanizada", além de sugerir uma impossibilidade da americanização do eu lírico, expõe o outro que faz as críticas, por este não compartilhar dessas coisas da terra. Esse outro é a elite, muito rica e com o burro do dinheiro. Essa verdade que indiretamente a letra da canção exprime é uma verdade sobre a identidade brasileira, sobre as suas antinomias. Se Carmen Miranda entrasse no Cassino da Urca com a intenção de colidir com o Estado Novo, de trazer à baila uma hipotética discordância 
com sua inclinação ao fascismo, seu "Good night, people" poderia ser entendido como um gesto de coragem, uma parrésia performática, dentro do discurso da performance artística. A própria letra de Disseram que eu voltei americanizada contorna a questão da legitimidade do discurso do nacional, da fratura que há entre o povo do discurso do Estado, no jargão popular o povão, e a nação como uma comunidade que abrange a todos. Este contorno é um contato e um desvio, pois sua via é subtextual, a crítica está implicada, mas não se dá de um modo direto, sincero, franco.

Para finalizar, considero importante enfatizar, mesmo que desviando o sentido do texto, a forma como se deu o processo identitário brasileiro, das muitas vozes, dos muitos tipos que poderiam representar esta brasilidade: coube ao samba, ao morador da periferia o posto de brasileiro típico. $\mathrm{O}$ Estado, a seu modo, aceitou este símbolo, embora tenha feito esforços para "civilizá-lo". Os meios de comunicação se adaptaram ao gosto popular pela imutável lei da oferta e da procura que orienta o mercado. E, por fim, a povo, aquele bem delimitado e isolado em lugar, via a si mesmo, nas letras das canções populares, pelo prisma dos artistas brasileiros. A imagem deste povo se orientava por uma representação cultural, cujos traços são mais ou menos delineados pela letra do samba de Paixa e Peixoto que oportunamente é citado para fechar este texto:

\footnotetext{
Mas pra cima de mim, pra que tanto veneno

Eu posso lá ficar americanizada

Eu que nasci com o samba e vivo no sereno

Topando a noite inteira a velha batucada

Nas rodas de malandro minhas preferidas

Eu digo mesmo eu te amo, e nunca "I love you"

Enquanto houver Brasil

$\mathrm{Na}$ hora da comidas

Eu sou do camarão ensopadinho com chuchu
}

\section{REFERÊNCIAS}

ANDERSON, Benedict. Comunidades imaginadas: reflexões sobre a origem e a expansão do nacionalismo. Lisboa: Edições 70, 2005.

CASTRO, Ruy. Carmen: uma biografia. São Paulo: Companhia das Letras. 2005.

MENDONÇA, Ana Rita. Carmen Miranda foi a Washington. Rio de Janeiro: Record, 1999.

FOUCAULT, M. Governo de si e dos outros. São Paulo: Martins Fontes, 2010. 